\title{
Sleep quality and circadian rhythm disruption in the intensive care unit: a review
}

This article was published in the following Dove Press journal:

Nature and Science of Sleep

10 November 2017

Number of times this article has been viewed

\author{
Yuliya Boyko' \\ Poul Jennum ${ }^{2}$ \\ Palle Toft ${ }^{\prime}$ \\ 'Department of Anesthesia and \\ Intensive Care Medicine, Odense \\ University Hospital, Odense, \\ Denmark, ${ }^{2}$ Department of Clinical \\ Neurophysiology, Danish Center \\ for Sleep Medicine, Rigshospitalet, \\ Glostrup, Denmark
}

Correspondence: Yuliya Boyko Department of Anesthesia and Intensive Care Medicine, Odense University Hospital, Soendre Blvd. 29, 5000 Odense C, Denmark $\mathrm{Tel}+454$ II 28794 Fax +4566113415 Email yuliya.boyko@rsyd.dk
Abstract: Sleep and circadian rhythm are reported to be severely abnormal in critically ill patients. Disturbed sleep can lead to the development of delirium and, as a result, can be associated with prolonged stay in the intensive care unit (ICU) and increased mortality. The standard criterion method of sleep assessment, polysomnography (PSG), is complicated in critically ill patients due to the practical challenges and interpretation difficulties. Several PSG sleep studies in the ICU reported the absence of normal sleep characteristics in many critically ill patients, making the standard method of sleep scoring insufficient in this patient group. Watson et al proposed a modified classification for sleep scoring in critically ill patients. This classification has not yet been validated. Sleep disturbance in the ICU is a multifactorial problem. The ICU environment, mechanical ventilation, medication, as well as the critical illness itself have been reported as important sleep disturbing factors. Secretion of sleep hormone, melatonin, expressing circadian rhythmicity was found abolished or phase delayed in critically ill patients. Various interventions have been tested in several studies aiming to improve sleep quality and circadian rhythm in the ICU. The results of these studies were inconclusive due to using the sleep assessment methods other than PSG or the absence of a reliable sleep scoring tool for the analysis of the PSG findings in this patient population. Development of a valid sleep scoring classification is essential for further sleep research in critically ill patients.

Keywords: critically ill patients, sleep patterns, polysomnography, environmental factors, mechanical ventilation, sedation; melatonin

\section{Introduction}

Sleep is crucial for the physical and mental health. Sleep deprivation is associated with the dysfunction of the immune and cardiovascular systems, disturbed metabolism, impaired memory and cognition, and increased mortality. ${ }^{1}$ There has been increased focus on sleep disturbances in the intensive care unit (ICU) due to the possible link between deprived sleep in critically ill patients and development of delirium, prolonged stay in the ICU, and increased mortality. ${ }^{2}$ Sleep and circadian rhythm in critically ill patients are reported to be severely disrupted with numerous arousals, shortage of deep sleep and rapid eye movement (REM) sleep, and abnormal diurnal distribution of sleep-wake periods. ${ }^{3-5}$

In this study, we aimed to summarize the present knowledge about sleep and circadian rhythm in critically ill patients including: 1) the challenges of sleep assessment and analysis in this patient group; 2) the role of possible sleep disturbing factors in the ICU, such as environmental factors, mechanical ventilation, and medication; 3) circadian process and melatonin; and 4) the role of critical illness. 


\section{Methods}

The knowledge on sleep in critically ill patients in the ICU is scarce and mostly based on observational studies and case series. Accordingly, the purpose of this overview was to introduce and discuss several aspects of the topic, and no traditional systematic approach was used.

PubMed database was searched for the following keywords and word combinations: sleep disturbances AND critically ill patients, sleep distubances AND ICU, sleep monitoring AND ICU, sleep AND ICU environment, sleep AND mechanical ventilation, sleep disturbances AND critically ill patients AND medication, sleep AND sedation, melatonin AND critically ill patients.

The literature search was limited to humans and adults (age $\geq 19$ years).

Primarily, the papers dealing with critically ill patients were included in this review as the sleep patterns in healthy volunteers exposed to the ICU environment cannot be compared with the patterns seen in critically ill patients' polysomnography (PSG). Sleep studies where PSG was used for sleep asessement were prioritiezed and mentioned more in detail. The interventional studies targeting sleep improvement in the ICU are listed in Table 1.

Table I Overview of studies testing sleep promoting interventions in the ICU

\begin{tabular}{|c|c|c|c|c|c|}
\hline Study & $\mathbf{n}$ & Design & Intervention & $\begin{array}{l}\text { Sleep } \\
\text { assessment } \\
\text { method }\end{array}$ & Results \\
\hline Scotto et $\mathrm{al}^{29}$ & 88 & $\begin{array}{l}\text { Quasi-experimental with } \\
\text { random assignment }\end{array}$ & Earplugs & Subjective & 个Sleep quality \\
\hline Van Rompaey et $\mathrm{al}^{30}$ & 136 & Randomized trial & Earplugs & Subjective & 个Sleep quality \\
\hline Richardson et $\mathrm{al}^{31}$ & 64 & Posttest quasi-experimental & Earplugs and eye masks & Subjective & 个Sleep quality in some patients \\
\hline Jones and Dawson ${ }^{32}$ & 100 & $\begin{array}{l}\text { Pre-/post-intervention service } \\
\text { evaluation }\end{array}$ & Earplugs and eye masks & Subjective & 个Sleep quality \\
\hline Le Guen et $\mathrm{al}^{33}$ & 41 & Randomized trial & Earplugs and eye masks & $\begin{array}{l}\text { Subjective and } \\
\text { actigraphy }\end{array}$ & 个Sleep quality \\
\hline Hu et $\mathrm{al}^{34}$ & 45 & Randomized trial & $\begin{array}{l}\text { Earplugs and eye masks } \\
\text { combined with } 30 \mathrm{~min} \\
\text { of relaxing music }\end{array}$ & Subjective & TSleep quality \\
\hline Patel et $\mathrm{al}^{35}$ & 59 & $\begin{array}{l}\text { Cohort-based study, pre-/post- } \\
\text { intervention evaluation }\end{array}$ & $\begin{array}{l}\text { Multicomponent } \\
\text { intervention }\end{array}$ & Subjective & 个Sleep quality \\
\hline Foreman et $\mathrm{al}^{18}$ & 12 & Randomized trial & $\begin{array}{l}\text { Headphones and eye } \\
\text { masks, and melatonin }\end{array}$ & PSG & $\begin{array}{l}\text { Incomparable due to abnormal sleep } \\
\text { EEG in many patients }\end{array}$ \\
\hline Boyko et $\mathrm{al}^{20}$ & 17 & Randomized crossover trial & $\begin{array}{l}\text { Multicomponent } \\
\text { intervention }\end{array}$ & PSG & $\begin{array}{l}\text { Incomparable due to abnormal sleep } \\
\text { EEG in many patients }\end{array}$ \\
\hline $\begin{array}{l}\text { Parthasarathy and } \\
\text { Tobin }^{36}\end{array}$ & II & Randomized crossover trial & $\begin{array}{l}\text { Assist-control, PS and } \\
\text { PS with added dead } \\
\text { space }\end{array}$ & PSG & 个Sleep quality with assist control \\
\hline Toublanc et $\mathrm{al}^{37}$ & 20 & Randomized crossover trial & $\begin{array}{l}\text { Assist-control and } \\
\text { low PS }\end{array}$ & PSG & 个Sleep quality with assist control \\
\hline Andrejak et $\mathrm{al}^{38}$ & 26 & Randomized crossover trial & $\begin{array}{l}\text { Pressure control } \\
\text { ventilation and low PS }\end{array}$ & PSG & 个Sleep quality with pressure control \\
\hline Roche-Campo et $\mathrm{al}^{39}$ & 16 & Randomized crossover trial & $\begin{array}{l}\text { Spontaneous ventilation } \\
\text { and low PS }\end{array}$ & PSG & 个Sleep quantity with PS \\
\hline Cabello et $\mathrm{al}^{40}$ & 15 & Randomized crossover trial & $\begin{array}{l}\text { Assist-control, clinically } \\
\text { adjusted PS, and } \\
\text { automatically adjusted PS }\end{array}$ & PSG & No difference \\
\hline Delisle et $\mathrm{al}^{4 \mathrm{I}}$ & 14 & Randomized crossover trial & NAVA and PS & PSG & 个Sleep quality with NAVA \\
\hline Fanfulla et $\mathrm{al}^{42}$ & 9 & Randomized crossover trial & $\begin{array}{l}\text { Noninvasive PS } \\
\text { ventilation: usual and } \\
\text { physiologic }\end{array}$ & PSG & 个Sleep quality with physiologic PS \\
\hline Kondili et al ${ }^{44}$ & 12 & Randomized trial & Propofol & PSG & $\downarrow$ Sleep quality \\
\hline Alexopoulou et $\mathrm{al}^{48}$ & 13 & $\begin{array}{l}\text { Nonrandomized, patients their } \\
\text { own controls }\end{array}$ & Dexmedetomidine & PSG & 个Sleep quality \\
\hline Ibrahim et $\mathrm{al}^{64}$ & 32 & Randomized trial & Melatonin & Subjective & No difference \\
\hline Shilo et $a^{63}$ & 8 & Randomized trial & Melatonin & Actigraphy & 个Sleep quality \\
\hline Bourne et $\mathrm{al}^{65}$ & 24 & Randomized trial & Melatonin & Bispectral index & 个Sleep quality \\
\hline
\end{tabular}

Note: $\uparrow$, increased; $\downarrow$, decreased.

Abbreviations: EEG, electroencephalography; ICU, intensive care unit; NAVA, neurally adjusted ventilation assist; PS, pressure support; PSG, polysomnography. 


\section{Sleep monitoring in the ICU}

Diverse methods of sleep assessment are used in critically ill patients. Subjective methods, including questionnaires and nurse registration forms, are widely used in the ICU due to the ease of approach and no requirement of special skills for the interpretation of results. Richard-Campbell Sleep Questionnaire, a five-item visual analog scale, is an example of the subjective method of sleep assessment in the ICU, based on patients' self-reports. It has been validated against PSG in alert, critically ill adults. ${ }^{6} \mathrm{~A}$ large number of critically ill patients have impaired consciousness or changed sensorium which makes the use of patients' self-reports unfeasible for sleep assessment. Results of the studies where the reliability of nurse's assessment of sleep/wake state has been tested are contradictory. ${ }^{711}$ Overestimation of sleep efficiency by nurses compared to the objective assessment was described in some studies. ${ }^{89}$ Insufficient or missing correlation of sleep/wake state and other sleep aspects assessed by nurses with PSG ${ }^{11}$ or inconsistency of nurses' evaluation with the objective findings in patients with abnormal electroencephalographic (EEG) patterns ${ }^{10}$ was reported in the other studies. The newer data of sleep monitoring in conscious, nonsedated, critically ill patients with PSG and nurse assessment support these observations (unpublished data, ClinicalTrials NCT02434341).

The alternative methods of sleep assessment are bispectral index (BIS) and actigraphy.

BIS is the EEG-derived method for the assessment of the depth of anesthesia. The method is sensitive to technical challenges and the interpretation is difficult. The use of BIS for sleep assessment is poorly documented. ${ }^{12,13}$

Actigraphy is based on the recording of patients' motor activity using a wrist or ankle device and gives information about sleep/wake state depending on the absence/presence of movements. ${ }^{14}$ As the ICU patients' movements are often limited, the reliability of this method for the indication of sleep/wake state as well as circadian pattern is poor.

In summary, BIS and actigraphy do not provide sufficient information about sleep architecture or circadian pattern.

PSG is a criterion standard method of sleep monitoring and the only method that allows for the assessment of sleep architecture. PSG is based on the recording of EEG together with several other physiologic signals (electrooculography, electromyography, electrocardiography, and respiratory parameters). The method is difficult to apply in the ICU due to technical and practical challenges. Critically ill patients are heavily monitored and often connected to diverse life supporting devices. The interactions with other electrical signals, mechanical or sweating artifacts make PSG recording in the ICU difficult. Critically ill patients are often unsettled or delirious and remove the leads, or feel more uncomfortable getting supplemental PSG leads. Additionally, analysis of the PSG recordings in critically ill patients is complicated. The previously used Rechtschaffen and Kales sleep scoring manual was replaced in 2007 by the American Academy of Sleep Medicine (AASM) sleep scoring classification. ${ }^{15}$ In accordance with the AASM criteria, sleep and wake cycle is divided into non (N)-REM and REM sleep, and wake, while NREM sleep is further subdivided into stages N1, N2, and N3. This classification relies on the interpretation of normal polygraphic signals including EEG; however, ICU patients often present abnormal EEG patterns.

Many attempts have been made to monitor critically ill patients' sleep by PSG. Besides severely abnormal hypnograms, including high arousal index, abnormal sleep stage shifts, and shortage or absence of restorative sleep (N3, REM), ${ }^{4,5,8,16,17}$ the absence of patterns described in the AASM classification was observed in many critically ill patients. ${ }^{3,18-21}$ In 2000, Cooper et al reported sleep patterns, as defined according to the standard classification, to be present only in 8 out of 20 critically ill mechanically ventilated patients ("disrupted sleep" group). ${ }^{3}$ The remaining patients were classified as "atypical sleep" and "coma" groups (including five and seven patients, respectively). The patients in the "atypical sleep" group and "coma" group had higher severity of critical illness scores and higher levels of sedation compared with the patients in the "disrupted sleep" group. The authors described the presence of "pathologic wakefulness" in some patients in the "atypical sleep" group: discrepancy of the EEG, showing slow wave activity, and behavioral aspects of wakefulness. In 2012, Drouot et al suggested two new states to be added to sleep scoring classification in critically ill patients - "atypical sleep" and "pathologic wakefulness". ${ }^{21}$ The authors analyzed PSG recordings of 57 conscious, nonsedated, critically ill patients on mechanical ventilation in the weaning phase (30 patients) or receiving noninvasive ventilation (27 patients). Standard sleep scoring classification could not be used in approximately one-third of these patients. Based on the previous suggestions, ${ }^{21}$ in 2013, Watson et al proposed a new sleep scoring classification for critically ill patients, subdividing atypical sleep into six further stages. ${ }^{19}$ The authors reported that 36 out of 37 critically ill, mechanically ventilated patients had atypical sleep patterns in the PSG recordings. The patients in this study had different levels of consciousness and sedation. We found Watson's sleep scoring classification useful for scoring sleep in critically ill patients if standard (AASM) 
classification was inapplicable in our PSG study from 2016 'Sleep in ICU and the role of environment'. ${ }^{20}$ Conscious, critically ill patients on mechanical ventilation participated in this study. Atypical sleep patterns were found in $\sim 70 \%$ of the patients. However, the role of Watson's classification in understanding sleep/wake pattern is not fully elucidated, for example, the interpretation of slow wave component in relation to sleep, encephalopathy, or medication is not completely clear. Watson's sleep scoring classification for critically ill patients has not yet been validated.

\section{Sleep and ICU environment}

Disturbed sleep in critically ill patients is caused by several factors. Environmental factors, such as noise, light, and interruptions, play a role in impairment of sleep and circadian rhythm. Sound levels in ICUs are reported to exceed the levels recommended by the World Health Organization. ${ }^{16,17,22-24}$ However, the significance of sleep disruptions caused by noise in critically ill patients has been discussed. Freedman et al recorded PSG and environmental noise in critically ill patients in medical ICU. ${ }^{17}$ The authors found only $11.5 \%$ and $17 \%$ of arousals and awakenings, respectively, to be associated with noise. Gabor et al monitored sleep by PSG in critically ill patients and healthy subjects exposed to ICU environment and recorded noise levels at the same time. Noise was reported to be responsible for the majority of arousals and awakenings in healthy subjects, but for the minority of these in critically ill patients. ${ }^{16}$ Elbaz et al reported increased incidence of arousals at sound levels above $77 \mathrm{dBC}$ in stable, mechanically ventilated patients in the weaning phase. Alarms were found to be the most significant source of noise. ${ }^{25}$

Fan et al studied light levels in an ICU and reported insufficient light exposure during the day time. ${ }^{26}$

Interruptions due to procedures are considered to be another important sleep disturbing factor in the ICU. Tamburri et al investigated the number of nocturnal care interactions in 50 patients in four different ICUs and found the mean number of interactions to be 42.6 per night. ${ }^{27}$ The same result was reported in the study by Ugras et al in a neurosurgical ICU. However, sleep disturbances were not associated with the frequency of nocturnal care interactions in this study, and the nurse care activities did not impact patient satisfaction. ${ }^{28}$

The effect of environmental interventions on sleep quality in critically ill patients has been tested in several studies. Earplugs, separately ${ }^{29,30}$ or in combination with other sleep promoting agents such as eye masks, ${ }^{31-33}$ were shown to improve sleep in the ICU. The application of earplugs and eye masks together with 30 min relaxing music was reported to promote sleep in cardiac surgical ICU. ${ }^{34}$ Improved sleep quality was found as a result of a multicomponent intervention directed on the reduction of light and noise in a mixed surgical/medical ICU. ${ }^{35}$ Subjective methods of sleep assessment alone or in combination with actigraphy were used in all the mentioned studies though.

PSG was used in the study by Foreman et al in the neurological ICU to control the environmental intervention, including noise-canceling head phones and eye masks together with melatonin administration. ${ }^{18}$ PSG recording of $65 \%$ of the patients was unscorable according to standard criteria. Accordingly, the effect of the intervention on sleep quality could not be assessed. Similar results on the effect of multicomponent environmental intervention in a mixed ICU, including reduction of noise and light levels and minimizing the number of nocturnal care interactions, were reported in the study by Boyko et al. ${ }^{20}$

\section{Sleep and mechanical ventilation}

Mechanical ventilation is considered to be another sleep disruptive factor in the ICU, mainly due to patient-ventilator asynchrony and hyperassistance resulting in central apneas. Different ventilator modes have been investigated in relation to sleep quality in critically ill patients. Controlled ventilator modes were reported to have positive effect on sleep quality in some studies. Parthasarathy and Tobin described significantly greater sleep fragmentation during pressure support ventilation (PSV) mode compared with assist-control ventilation (ACV) in sedated, critically ill patients. ${ }^{36}$ Toublanc et al reported significant increase in stage 1 and 2 NREM sleep and reduction in wakefulness during the first part of the night and increase in stage 3 and 4 NREM sleep during the second part of the night with ACV compared with PSV in nonsedated, critically ill patients weaning from mechanical ventilation. ${ }^{37}$ Improved sleep quantity and quality during pressure control mode compared with support mode were described in the study by Andrejak et al in nonsedated patients weaning from mechanical ventilation. ${ }^{38}$ PSV was associated with better sleep quantity but not quality compared with spontaneous ventilation in nonsedated, tracheostomized patients in the weaning period in the study by Roche-Campo et al. ${ }^{39}$

Inconsistent with the mentioned papers, Cabello et al could not show any difference in sleep quality on comparing ACV with clinically and automatically adjusted PSV in conscious, mechanically ventilated patients. ${ }^{40}$

Advantages of the more physiologic modes of mechanical ventilation, such as neutrally adjusted ventilatory assist ${ }^{41}$ and 
physiologic noninvasive $\mathrm{PSV},{ }^{42}$ on sleep quality were reported in some studies. Improved sleep quality was explained by decreased patient-ventilator asynchrony and reduction of the ineffective efforts.

\section{Sleep and medication}

Sedation is widely used in intensive care setting, mostly in patients on mechanical ventilation to remove the discomfort caused by endotracheal tube and the ventilation problems caused by patient-ventilator asynchrony. The commonly used sedative agents, such as propofol, opioids, and benzodiazepines, are known to impact sleep quality. Propofol and benzodiazepines, which are gamma-aminobutyric acid-A receptor agonists, were shown to reduce REM sleep in critically ill patients. ${ }^{43,44}$ Benzodiazepines were reported to have deliriogenic effect as well. ${ }^{43}$ The central nervous system opioid receptor agonists were shown to decrease REM sleep. ${ }^{45,46}$

A selective $\alpha 2$-receptor agonist dexmedetomidine has recently been in focus as a newer promising sedative agent in the ICU. Nighttime infusion of dexmedetomidine has been shown in a few studies to induce sleep during the nighttime period $^{47,48}$ and to increase the N2 sleep stage of NREM sleep, ${ }^{47-49}$ though it does not increase the restorative sleep stages.

Various other medications, such as vasoactive drugs, amiodarone, antibiotics, and corticosteroids, often used in critically ill patients and known to impact the sleep quality, contribute to sleep disturbances seen in this patient population. ${ }^{50}$

\section{Melatonin}

Melatonin is a sleep hormone secreted in the pineal gland located in the epithalamus. Melatonin production is regulated through the intern pacemaker located in suprachiasmatic nucleus and is influenced by light. Melatonin participates in the regulation of diurnal sleep/wake cycle. Melatonin secretion varies during the day: the secretion increases during the night hours and decreases during the day hours. Melatonin secretion pattern can be assessed by detection of melatonin in serum or saliva or measurement of melatonin metabolite 6-sulfatoxymelatonin (6-SMT) in urine. ${ }^{51}$

Melatonin secretion pattern has been studied in different groups of critically ill patients. The results of these studies are conflicting. Abolished rhythmicity in melatonin secretion pattern in critically ill patients was reported in several studies. Shilo et al found missing nocturnal melatonin top in critically ill patients requiring ventilator support. ${ }^{52}$ Frisk et al reported lower levels of excreted 6-SMT associated with mechanical ventilation and higher levels associated with benzodiazepines. ${ }^{53}$ Abolished rhythmicity of melatonin secretion without association with sedation in sedated, critically ill patients on mechanical ventilation was reported by Olofsson et al. ${ }^{54}$ Paul et al compared serum melatonin levels in sedated, critically ill patients with and without brain injury and found disturbed secretion in both groups, though lower melatonin levels were found in the group with brain injury. ${ }^{55}$ Disturbed circadian rhythm in septic, critically ill patients, as measured by 6-SMT excretion, was reported in two studies. ${ }^{56,57}$ The majority of patients in these studies were sedated and on mechanical ventilation. Preserved rhythmicity of melatonin production was found in critically ill patients without sepsis. ${ }^{57}$

Sustained diurnal pattern of melatonin secretion assessed by 6-SMT excretion was found in two studies. ${ }^{58,59}$ The study by Riutta et al was performed in nonseptic, critically ill patients, where 20 out of 40 patients were on mechanical ventilation and 25 patients were benzodiazepine sedated. ${ }^{58}$ The majority of patients in the study by Gehlbach et al were sedated and mechanically ventilated. ${ }^{59}$ Urine samples were collected at hourly intervals. The authors reported preserved but phase-delayed 6-SMT excretion in the majority of patients. Boyko et al reported preserved but phase-delayed melatonin secretion pattern measured by serum melatonin in mechanically ventilated, critically ill patients. ${ }^{60}$

The reports about the correlation of the severity of critical illness and melatonin secretion are contradictory as well. No correlation of melatonin secretion pattern with the severity of critical illness scores was reported in several studies. ${ }^{53,58-60}$ Negative correlation between the melatonin levels and Acute Physiology and Chronic Health Evaluation (APACHE) score was reported in septic patients in the study by Perras et al. ${ }^{61}$

Abolished regulation of diurnal pattern of melatonin secretion in critically ill patients by light and darkness was reported in two studies: in patients with severe sepsis in the study by Verceles et $\mathrm{al}^{56}$ and in critically ill patients of different age groups in the study by Perras et al. ${ }^{62}$

Exogenous melatonin was reported to improve sleep in critically ill patients in three studies. Shilo et al found increased sleep duration and sleep quality with $3 \mathrm{mg}$ melatonin, assessed by actigraphy, in critically ill patients with chronic obstructive pulmonary disease. ${ }^{63}$ Ibrahim et al found no differences in subjectively assessed sleep in two groups of tracheostomized, critically ill patients after administration of $3 \mathrm{mg}$ melatonin. ${ }^{64}$ Bourne et al reported improved sleep efficiency with $10 \mathrm{mg}$ melatonin in mechanically ventilated, critically ill patients in the weaning period. ${ }^{65}$ Sleep was monitored by BIS in this study, though, as mentioned above, subjective methods, BIS, and actigraphy cannot be considered reliable for sleep assessment in critically ill patients. 
No PSG studies have yet been published reporting the effect of melatonin treatment on sleep in the ICU.

\section{Sleep and critical illness}

Sleep disturbances in critically ill patients are multifactorial. Environmental factors, mechanical ventilation, and medication play an important role in sleep disruption in this patient population. Nevertheless, the other mechanisms, such as critical illness itself, are worth consideration. Higher severity of critical illness scores were reported to be associated with disrupted sleep in critically ill patients in the previous papers by Gabor et a ${ }^{16}$ and Fanfulla et al ${ }^{66}$ Atypical sleep or missing characteristics of normal sleep were found to be associated with higher Acute Physiology Score and higher APACHE II score in the studies by Cooper et $\mathrm{al}^{3}$ and Foreman et al, ${ }^{18}$ respectively. Sedated patients and patients with affected levels of consciousness participated in these studies. Association of atypical sleep with higher critical illness scores was investigated in a recent PSG study of sleep in conscious, critically ill patients on mechanical ventilation by Boyko et al. The results of this study have not yet been published (ClinicalTrials NCT02434341).

\section{Conclusion}

Sleep and circadian rhythm are severely abnormal in critically ill patients due to a number of factors such as intensive care environment, including noise and procedures, mechanical ventilation, and medication. However, the severity of critical illness is associated with abnormal sleep patterns in this patient population as well. PSG, the criterion standard method for sleep monitoring, is challenging in the ICU. Currently, there are no validated methods of sleep scoring for this patient population, resulting in the difficulties in testing sleep promoting interventions. Further development of a reliable method of scoring critically ill patients' PSGs and the analysis of PSG patterns associated with outcomes is the next step in sleep research in the ICU.

\section{Disclosure}

The authors report no conflicts of interest in this work.

\section{References}

1. Mukherjee S, Patel SR, Kales SN, et al; American Thoracic Society ad hoc Committee on Healthy Sleep. An Official American Thoracic Society Statement: the importance of healthy sleep. Recommendations and future priorities. Am J Respir Crit Care Med. 2015;191(12):1450-1458.

2. Ely EW, Shintani A, Truman B, et al. Delirium as a predictor of mortality in mechanically ventilated patients in the intensive care unit. JAMA. 2004;291(14):1753-1762.
3. Cooper AB, Thornley KS, Young GB, Slutsky AS, Stewart TE, Hanly PJ. Sleep in critically ill patients requiring mechanical ventilation. Chest. 2000;117(3):809-818.

4. Elliott R, McKinley S, Cistulli P, Fien M. Characterisation of sleep in intensive care using 24-hour polysomnography: an observational study. Crit Care. 2013;17(2):R46.

5. Hilton BA. Quantity and quality of patients' sleep and sleep-disturbing factors in a respiratory intensive care unit. $J$ Adv Nurs. 1976;1(6): 453-468.

6. Richards KC, O'Sullivan PS, Phillips RL. Measurement of sleep in critically ill patients. J Nurs Meas. 2000;8(2):131-144.

7. Edwards GB, Schuring LM. Pilot study: validating staff nurses' observations of sleep and wake states among critically ill patients, using polysomnography. Am J Crit Care. 1993;2(2):125-131.

8. Aurell J, Elmqvist D. Sleep in the surgical intensive care unit: continuous polygraphic recording of sleep in nine patients receiving postoperative care. Br Med J (Clin Res Ed). 1985;290(6474):1029-1032.

9. Bourne RS, Minelli C, Mills GH, Kandler R. Clinical review: sleep measurement in critical care patients: research and clinical implications. Critical Care. 2007;11(4):226.

10. Boesen HC, Andersen JH, Bendtsen AO, Jennum PJ. Sleep and delirium in unsedated patients in the intensive care unit. Acta Anaesthesiol Scand. 2016;60(1):59-68.

11. Ritmala-Castren M, Virtanen I, Vahlberg T, Leivo S, Kaukonen KM, Leino-Kilpi H. Evaluation of patients' sleep by nurses in an ICU.J Clin Nurs. 2016;25(11-12):1606-1613.

12. Nieuwenhuijs D, Coleman EL, Douglas NJ, Drummond GB, Dahan A. Bispectral index values and spectral edge frequency at different stages of physiologic sleep. Anesth Analg. 2002;94(1):125-129.

13. Gimenez S, Romero S, Alonso JF, et al. Monitoring sleep depth: analysis of bispectral index (BIS) based on polysomnographic recordings and sleep deprivation. J Clin Monit Comput. 2017;31(1):103-110.

14. Kamdar BB, Kadden DJ, Vangala S, et al. Feasibility of Continuous Actigraphy in Patients in a Medical Intensive Care Unit. Am J Crit Care. 2017;26(4):329-335.

15. Silber MH, Ancoli-Israel S, Bonnet MH, et al. The visual scoring of sleep in adults. J Clin Sleep Med. 2007;3(2):121-131.

16. Gabor JY, Cooper AB, Crombach SA, et al. Contribution of the intensive care unit environment to sleep disruption in mechanically ventilated patients and healthy subjects. Am J Respir Crit Care Med. 2003;167(5):708-715.

17. Freedman NS, Gazendam J, Levan L, Pack AI, Schwab RJ. Abnormal sleep/wake cycles and the effect of environmental noise on sleep disruption in the intensive care unit. Am J Respir Crit Care Med. 2001;163(2):451-457.

18. Foreman B, Westwood AJ, Claassen J, Bazil CW. Sleep in the neurological intensive care unit: feasibility of quantifying sleep after melatonin supplementation with environmental light and noise reduction. J Clin Neurophysiol. 2015;32(1):66-74.

19. Watson PL, Pandharipande P, Gehlbach BK, et al. Atypical sleep in ventilated patients: empirical electroencephalography findings and the path toward revised ICU sleep scoring criteria. Crit Care Med. 2013;41(8):1958-1967.

20. Boyko Y, Jennum P, Nikolic M, Holst R, Oerding H, Toft P. Sleep in intensive care unit: The role of environment. J Crit Care. 2016;37:99-105.

21. Drouot X, Roche-Campo F, Thille AW, et al. A new classification for sleep analysis in critically ill patients. Sleep Med. 2012;13(1):7-14.

22. Darbyshire JL, Young JD. An investigation of sound levels on intensive care units with reference to the WHO guidelines. Crit Care. 2013;17(5):R187.

23. Aaron JN, Carlisle CC, Carskadon MA, Meyer TJ, Hill NS, Millman RP. Environmental noise as a cause of sleep disruption in an intermediate respiratory care unit. Sleep. 1996;19(9):707-710.

24. Tainter CR, Levine AR, Quraishi SA, et al. Noise levels in surgical ICUs are consistently above recommended standards. Crit Care Med. 2016;44(1):147-152. 
25. Elbaz M, Leger D, Sauvet F, et al. Sound level intensity severely disrupts sleeep in ventilated ICU patients throughout a 24 -h period: a preliminary 24-h study of sleep stages and associated sound levels. Ann Intensive Care. 2017;7(1):25.

26. Fan EP, Abbott SM, Reid KJ, Zee PC, Maas MB. Abnormal environmental light exposure in the intensive care environment. $J$ Crit Care. 2017;40:11-14.

27. Tamburri LM, DiBrienza R, Zozula R, Redeker NS. Nocturnal care interactions with patients in critical care units. Am J Crit Care. 2004;13(2):102-112; quiz 114-5.

28. Uğraş GA, Babayigit S, Tosun K, Aksoy G, Turan Y. The effect of nocturnal patient care interventions on patient sleep and satisfaction with nursing care in neurosurgery intensive care unit. J Neurosci Nurs. 2015;47(2):104-112.

29. Scotto CJ, McClusky C, Spillan S, Kimmel J. Earplugs improve patients' subjective experience of sleep in critical care. Nurs Crit Care. 2009;14(4):180-184

30. Van Rompaey B, Elseviers MM, Van Drom W, Fromont V, Jorens PG. The effect of earplugs during the night on the onset of delirium and sleep perception: a randomized controlled trial in intensive care patients. Crit Care. 2012;16(3):R73.

31. Richardson A, Allsop M, Coghill E, Turnock C. Earplugs and eye masks: do they improve critical care patients' sleep? Nurs Crit Care. 2007;12(6):278-286.

32. Jones C, Dawson D. Eye masks and earplugs improve patient's perception of sleep. Nurs Crit Care. 2012;17(5):247-254.

33. Le Guen M, Nicolas-Robin A, Lebard C, Arnulf I, Langeron O. Earplugs and eye masks vs routine care prevent sleep impairment in post-anaesthesia care unit: a randomized study. Br JAnaesth. 2014;112(1):89-95.

34. Hu RF, Jiang XY, Hegadoren KM, Zhang YH. Effects of earplugs and eye masks combined with relaxing music on sleep, melatonin and cortisol levels in ICU patients: a randomized controlled trial. Crit Care. 2015;19:115

35. Patel J, Baldwin J, Bunting P, Laha S. The effect of a multicomponent multidisciplinary bundle of interventions on sleep and delirium in medical and surgical intensive care patients. Anaesthesia. 2014;69(6):540-549.

36. Parthasarathy S, Tobin MJ. Effect of ventilator mode on sleep quality in critically ill patients. Am J Respir Crit Care Med. 2002;166(11): 1423-1429.

37. Toublanc B, Rose D, Glerant JC, et al. Assist-control ventilation vs. low levels of pressure support ventilation on sleep quality in intubated ICU patients. Intensive Care Med. 2007;33(7):1148-1154.

38. Andrejak C, Monconduit J, Rose D, et al. Does using pressure-controlled ventilation to rest respiratory muscles improve sleep in ICU patients? Respir Med. 2013;107(4):534-541.

39. Roche-Campo F, Thille AW, Drouot X, et al. Comparison of sleep quality with mechanical versus spontaneous ventilation during weaning of critically III tracheostomized patients. Crit Care Med. 2013;41(7): 1637-1644.

40. Cabello B, Thille AW, Drouot X, et al. Sleep quality in mechanically ventilated patients: comparison of three ventilatory modes. Crit Care Med. 2008;36(6):1749-1755.

41. Delisle S, Ouellet P, Bellemare P, Tetrault JP, Arsenault P. Sleep quality in mechanically ventilated patients: comparison between NAVA and PSV modes. Ann Intensive Care. 2011;1(1):42.

42. Fanfulla F, Delmastro M, Berardinelli A, Lupo ND, Nava S. Effects of different ventilator settings on sleep and inspiratory effort in patients with neuromuscular disease. Am J Respir Crit Care Med. 2005;172(5):619-624.

43. Trompeo AC, Vidi Y, Locane MD, et al. Sleep disturbances in the critically ill patients: role of delirium and sedative agents. Minerva Anestesiol. 2011;77(6):604-612.

44. Kondili E, Alexopoulou C, Xirouchaki N, Georgopoulos D. Effects of propofol on sleep quality in mechanically ventilated critically ill patients: a physiological study. Intensive Care Med. 2012;38(10):1640-1646.
45. Mortazavi S, Thompson J, Baghdoyan HA, Lydic R. Fentanyl and morphine, but not remifentanil, inhibit acetylcholine release in pontine regions modulating arousal. Anesthesiology. 1999;90(4):1070-1077.

46. Bonafide CP, Aucutt-Walter N, Divittore N, King T, Bixler EO, Cronin AJ. Remifentanil inhibits rapid eye movement sleep but not the nocturnal melatonin surge in humans. Anesthesiology. 2008;108(4):627-633.

47. Oto J, Yamamoto K, Koike S, Onodera M, Imanaka H, Nishimura M. Sleep quality of mechanically ventilated patients sedated with dexmedetomidine. Intensive Care Med. 2012;38(12):1982-1989.

48. Alexopoulou C, Kondili E, Diamantaki E, et al. Effects of dexmedetomidine on sleep quality in critically ill patients: a pilot study. Anesthesiology. 2014;121(4):801-807.

49. Huupponen E, Maksimow A, Lapinlampi P, et al. Electroencephalogram spindle activity during dexmedetomidine sedation and physiological sleep. Acta Anaesthesiol Scand. 2008;52(2):289-294.

50. Bourne RS, Mills GH. Sleep disruption in critically ill patients pharmacological considerations. Anaesthesia. 2004;59(4):374-384.

51. Benloucif S, Burgess HJ, Klerman EB, et al. Measuring melatonin in humans. J Clin Sleep Med. 2008;4(1):66-69.

52. Shilo L, Dagan Y, Smorjik Y, et al. Patients in the intensive care unit suffer from severe lack of sleep associated with loss of normal melatonin secretion pattern. Am J Med Sci. 1999;317(5):278-281.

53. Frisk U, Olsson J, Nylen P, Hahn RG. Low melatonin excretion during mechanical ventilation in the intensive care unit. Clin Sci (Lond). 2004;107(1):47-53.

54. Olofsson K, Alling C, Lundberg D, Malmros C. Abolished circadian rhythm of melatonin secretion in sedated and artificially ventilated intensive care patients. Acta Anaesthesiol Scand. 2004;48(6):679-684.

55. Paul T, Lemmer B. Disturbance of circadian rhythms in analgosedated intensive care unit patients with and without craniocerebral injury. Chronobiol Int. 2007;24(1):45-61.

56. Verceles AC, Silhan L, Terrin M, Netzer G, Shanholtz C, Scharf SM. Circadian rhythm disruption in severe sepsis: the effect of ambient light on urinary 6-sulfatoxymelatonin secretion. Intensive Care Med. 2012;38(5):804-810.

57. Mundigler G, Delle-Karth G, Koreny M, et al. Impaired circadian rhythm of melatonin secretion in sedated critically ill patients with severe sepsis. Crit Care Med. 2002;30(3):536-540.

58. Riutta A, Ylitalo P, Kaukinen S. Diurnal variation of melatonin and cortisol is maintained in non-septic intensive care patients. Intensive Care Med. 2009;35(10):1720-1727.

59. Gehlbach BK, Chapotot F, Leproult R, et al. Temporal disorganization of circadian rhythmicity and sleep-wake regulation in mechanically ventilated patients receiving continuous intravenous sedation. Sleep. 2012;35(8):1105-1114.

60. Boyko Y, Holst R, Jennum P, Oerding H, Nikolic M, Toft P. Melatonin secretion pattern in critically ill patients: A Pilot Descriptive Study. Crit Care Res Pract. 2017;2017:7010854.

61. Perras B, Kurowski V, Dodt C. Nocturnal melatonin concentration is correlated with illness severity in patients with septic disease. Intensive Care Med. 2006;32(4):624-625.

62. Perras B, Meier M, Dodt C. Light and darkness fail to regulate melatonin release in critically ill humans. Intensive Care Med. 2007;33(11):1954-1958.

63. Shilo L, Dagan Y, Smorjik Y, et al. Effect of melatonin on sleep quality of COPD intensive care patients: a pilot study. Chronobiol Int. 2000;17(1):71-76.

64. Ibrahim MG, Bellomo R, Hart GK, et al. A double-blind placebocontrolled randomised pilot study of nocturnal melatonin in tracheostomised patients. Crit Care Resusc. 2006;8(3):187-191.

65. Bourne RS, Mills GH, Minelli C. Melatonin therapy to improve nocturnal sleep in critically ill patients: encouraging results from a small randomised controlled trial. Critical Care. 2008;12(2):R52.

66. Fanfulla F, Ceriana P, D'Artavilla Lupo N, Trentin R, Frigerio F, Nava S Sleep disturbances in patients admitted to a step-down unit after ICU discharge: the role of mechanical ventilation. Sleep. 2011;34(3):355-362. 


\section{Publish your work in this journal}

Nature and Science of Sleep is an international, peer-reviewed, open access journal covering all aspects of sleep science and sleep medicine, including the neurophysiology and functions of sleep, the genetics of sleep, sleep and society, biological rhythms, dreaming, sleep disorders and therapy, and strategies to optimize healthy sleep. The manuscript management system is completely online and includes a very quick and fair peer-review system, which is all easy to use. Visit http://www dovepress.com/testimonials.php to read real quotes from published authors.

Submit your manuscript here: https://www.dovepress.com/nature-and-science-of-sleep-journal 